\title{
AN INVESTIGATION OF THE INTERACTION OF CLASS \\ ATTENDANCE, TUTORIALS, MENTOR SESSIONS, VIDEO \\ PRESENTATIONS AND EXTERNAL TUTORING, AND THE \\ EFFECT THEREOF ON STUDENT PERFORMANCE
}

\author{
J. M. Ontong* \\ e-mail: ontongi@sun.ac.za / https://orcid.org/0000-0001-5097-8988
}

\author{
A. Bruwer* \\ e-mail: bruwera@sun.ac.za / https://orcid.org/0000-0002-0951-8397
}

\author{
J. A. Dreyer* \\ e-mail: jdreyer@sun.ac.za / https://orcid.org/0000-0002-5716-4263
}

*School of Accountancy

Stellenbosch University

Stellenbosch, South Africa

\section{ABSTRACT}

The need to improve the systematic failures of higher education has led to various studies that promote the implementation of certain types of teaching interventions with the aim of increasing student performance. This study investigates the effects of these interventions on student performance in a multiple-intervention environment by developing an attendance construct proxy, as well as an alternative to the class attendance intervention construct proxy. The benefits of these interventions were analysed to determine whether certain interventions have a more significant impact on student performance than others in the context of increasing student performance. Using a survey approach to determine the record of participation in the interventions by the students, the findings of participation were analysed using the academic records of the students to identify the effect. The results suggest that increased levels of attending classes, which include traditional and additional face-to-face sessions, have a significant positive effect on student performance. When analysing the additional face-to-face sessions, specifically the further class attendance of tutorial classes where students are given the opportunity to work on their own or in groups and only request assistance where needed, the greatest significant positive effect on student performance was observed. The findings further suggest that certain interventions - often seen as alternatives to class attendance, such as attending mentor sessions, external tutoring, and watching videos of beginners' classes - do not necessarily have a positive significant effect on student performance. Interestingly, the perceptions of students are consistent with the findings of the study, with the majority of students not recommending the use of external tutoring services. The findings of the study therefore provide insightful value to the design of modules at higher 
education institutions, aiding in identifying and responding to which interventions would have a significant impact on student performance.

Keywords: academic performance, accounting, lecture attendance, mentoring, tutorials

\section{INTRODUCTION}

The long-running recognition of the traditional class format as a method suited only to the learning styles and preferences of a certain group of students has highlighted the need for additional teaching interventions. This was done by customising either the traditional class format or adding academic aids to the traditional class format (Steenkamp and Wessels 2009, 117). Understanding the effect of class attendance, as well as the introduction of various teaching interventions such as tutoring and mentoring, on student performance at undergraduate level has received attention in the existing literature (Cooke and Wallace 1990, 79; Steenkamp and Wessels 2009, 117; Van Walbeek 2004, 861; Schmulian and Coetzee 2011, 178; De Jager and Blitzer 2013, 399; Mahlangu and Fraser 2017, 104; Papageorgiou 2019, 262). The findings of the literature suggest positive and significant benefits for student performance for traditional class attendance, as well as all academic aid interventions adopted (Steenkamp and Wessels 2009, 117; Van Walbeek 2004, 861; De Jager and Blitzer 2013, 399; Mahlangu and Fraser 2017 , 104). It is concerning that although the literature is rich with suggestions for various teaching interventions, the Council on Higher Education (CHE) has highlighted the systemic failure of universities to graduate students, with universities achieving low throughput rates of students from the first year, which suggests that further investigation is required to analyse the impact, and success of, interventions on student performance in terms of academic success (CHE 2013, 8). The literature often suggests various interventions in isolation; this study differs in that it is set in an environment where multiple teaching interventions are implemented. This environment thus allows the investigation as to which of the interventions would provide significant benefits for student performance and which of these represent insignificant and consequently less meaningful contributions to student performance in a multiple-academic aid interventions type of environment.

This study has therefore identified an introduction to the Financial Accounting module at Stellenbosch University as its focus area. This module has various interventions available, provided through both internal university channels and external channels. Students have access to various teaching interventions, such as extra classes, peer tutoring and mentor sessions, and video recordings; each of which was implemented to assist students to achieve success through improved academic performance. This study seeks to add to the body of literature by performing an investigation on the effect of various teaching interventions classified in terms 
of two self-developed constructs, namely attendance of classes and alternatives to class attendance, on student performance. The study further examines student perceptions of externally offered services. The findings of this study provide insight for academics interested in engaging in course renewal and could assist with the understanding of the effect of the interaction of various teaching interventions on student performance. This study further assists academics to understand the interaction of interventions, such as the recommendation of using external tutor services by students and the interaction with class attendance.

\section{BACKGROUND TO THE INTRODUCTORY FINANCIAL ACCOUNTING MODULE}

Financial Accounting 188 is a full-year module offered by Stellenbosch University and focuses on an introduction to financial accounting. The focus group for this study was the students enrolled in the 2018 Financial Accounting 188 module. The module was offered to a group of 1233 students in 2018. The module is offered in both English and Afrikaans, with the total number of students being divided into six class groups. These class groups had an average venue size ranging from 80 to 360 seats. The module is presented in the format of four compulsory traditional lectures a week, with one additional voluntary practical tutorial class period per week, and one additional class (the beginners' class) focusing purely on how to approach questions and completing these questions per week. ${ }^{1}$

All traditional lectures are presented from the same set of module slides and follow the same weekly academic programme. The style and approach of the traditional lectures are planned and discussed on a weekly basis by the lecturers of the module. The tutorial class period is a structured academic support programme implemented in 2008, and commences in the second week of the academic year. Students are encouraged to complete a textbook-style question paper on their own, with full access to their notes, and are allowed to ask for assistance from a lecturer, senior student, or peer, should a question arise. No additional theory or content presentation is done in the tutorial classes. In addition to the peer assistance in the tutorial classes, an additional peer mentoring programme (mentor programme) was established in 2009. The mentor programme offers various one-hour sessions throughout the week at either $1 \mathrm{pm}$ or $5 \mathrm{pm}$. The mentor programme allows students to voluntarily attend mentoring sessions by senior students in small groups (maximum of 15 students). The aim of these mentoring sessions is for students to be given the opportunity to receive tutoring from senior students who have previously completed the module. The mentor session is deemed a study aid and support to the students without taking on the form of a class. The beginners' class is a class focused on the threshold concepts of the topic lectured during the week's traditional lectures and the application thereof in questions. 
Analysing the nature of the three types of classes indicates that traditional classes are both theory and practice based; however, students are guided as to how questions should be answered with very little individual or group work. Beginners' classes are purely practical classes with limited revision of theory and with very little individual or group work, whereas tutorial classes are purely practical exercises, where assignments are completed individually or in groups, with lecturer assistance provided only when needed. Various external tutors also offer tutoring services at a fee, as well as crash courses prior to assessments. ${ }^{2}$ Table 1 illustrates the number of sessions provided for each of the class types.

Table 1: Number of sessions provided

\begin{tabular}{|l|l|}
\hline \multicolumn{1}{|c|}{ Intervention } & \multicolumn{1}{c|}{ Number of occurrences } \\
\hline Traditional lecturers & 4 sessions a week $(\mathrm{n}=102$ for the year $)$ \\
\hline Beginners' classes & 1 session a week $(\mathrm{n}=20$ for the year $)$ \\
\hline Tutorial classes & $1^{3}$ session a week $(\mathrm{n}=23$ for the year $)$ \\
\hline Mentor programmes & 1 session a week \\
\hline Beginners' videos & 20 videos for the year \\
\hline Revision videos & 11 videos for the year \\
\hline
\end{tabular}

To evaluate the impact of these classes as academic interventions on students' performance, the study begins with an introduction that discusses the research problem and background to the module. This is followed by a review of the existing literature, which provides an overview of existing studies in this field. This leads to a descriptive and statistical analysis of the data used. Lastly, a summary of the findings and conclusion is provided.

\section{LITERATURE REVIEW}

A strong body of literature exists in that various studies have identified the effect of various teaching interventions on student performance (Steenkamp and Wessels 2009, 117; Van Walbeek 2004, 861; De Jager and Blitzer 2013, 399; Mahlangu and Fraser 2017, 104). The majority of these studies have identified and evaluated a single factor of academic aid intervention, such as class attendance, when analysing the impact on student performance (Schmulian and Coetzee 2011, 178; Papageorgiou 2019, 262). The various teaching interventions identified as part of the literature review are discussed below.

\section{Class attendance and absenteeism}

Various studies have evaluated the effect of class attendance and absenteeism in a traditional class environment on student performance. These studies have found strong empirical evidence 
of a positive influence (Devadoss and Foltz 2006, 499; Schmulian and Coetzee 2011, 178; Steenkamp, Baard and Frick 2015, 113; Papageorgiou 2019, 262). Based on these findings, there have been suggestions by researchers such as Romer $(1993,167)$ that attendance should be made mandatory in an undergraduate course, given the strong statistical empirical evidence of a relationship between absenteeism and performance. Mandatory attendance has, however, created a negative perception among students regarding class attendance, while Bignoux and Sund $(2018,703)$ have noted that carefully crafted attendance policies can have a positive effect on students' academic performance. Van Walbeek $(2004,861)$ conducted a study using an online survey and found that tutorial attendance, in addition to traditional lecturer attendance, has a strong positive influence on students' academic performance. Horn and Jansen (2009, 179) conducted a similar study within a first-year economic module, and also found a strong positive influence of tutorial attendance on students' academic performance.

\section{Mentor sessions and external tutoring}

De Jager and Blitzer $(2013,399)$ found that students who participated in small group learning such as peer student assistance, mentoring, and external tutoring experienced a positive effect on their academic performance. Colver and Fry $(2016,16)$ examined the effect of undergraduate peer tutoring on student performance and found a significant positive relationship between peer tutoring and student performance measured by final course outcomes. It was noted that tutoring was especially beneficial for first-generation higher education students. The mentor programme within the Financial Accounting module provides students this peer tutoring academic aid as an optional component to the tutorial sessions. Sriprakash, Proctor and $\mathrm{Hu}(2016,426)$ found that paid tutoring is a strategy that is engaged in an attempt to secure a certain educational advantage, noting that individuals often seek to make use of paid private tutoring as a method to compensate for the perceived lack of teaching in the traditional schooling approach. Students have therefore developed their own intervention in order to adapt the traditional lecture approach to their personal learning styles.

\section{Other forces}

Class attendance and specific academic interventions have been known to directly influence students' academic performance. Various other studies have, however, indicated that there are certain indirect components or previous interventions, academic or emotional, that might influence student performance as well. It has been suggested that a student's final-year high school performance could be a predictor of student performance in their first-year undergraduate level modules. Van Walbeek $(2004,861)$ found a positive correlation between 
students' performance in Grade 12 mathematics and their academic performance in first-year undergraduate modules. Bokana and Tewari $(2014,259)$ expanded on the literature by performing an econometric analysis with findings that suggested that a student's total matriculation points, and Grade 12 mathematics and English grades, are determinants of success in a first-year module. Mahlangu and Fraser $(2017,104)$, however, conducted a study among top-performing final-year high school achievers, finding that their results in first-year undergraduate modules were influenced by students' self-discipline, self-motivation, interest in the course, self-confidence, academic preparedness, and effort, as well as the beliefs the students have about themselves. Mahlangu and Fraser $(2017,104)$ emphasised the significant influence of positive "compelling forces" at universities that assist first-year students in adapting to the university environment; hinting that prior performance has less significance than has been previously indicated by the body of existing literature. As the university module used in this study is an introductory module to financial accounting, covering work similar to what students could potentially have covered in high school, the prior exposure that certain students in the study had to accounting education was taken into account by performing the study in three groups. Firstly, the overall group; secondly, the overall group split into a group that had prior exposure to accounting; and thirdly, another group that had no prior exposure to accounting.

The findings of existing literature therefore create a continued platform for debate on the variety of interventions that determine students' academic success in terms of increased student performance. This study, incorporating considerations of the existing literature, aims to add to the literature by performing an analysis on actual data in an environment where multiple teaching interventions are offered in order to critically evaluate the effect of these various teaching interventions' on student performance in a first-year accounting module at a South African university. The interaction of various interventions in a multiple-intervention environment is limited in the literature.

\section{RESEARCH METHODOLOGY}

\section{Overview}

The methodology utilised a combination of qualitative data in the form of student perceptions, as well as quantitative data obtained via an electronic survey completed by students who were enrolled in the 2018 Financial Accounting 188 module. The use of the survey allowed the researchers to obtain a comprehensive understanding per respondent of the level of engagement and use of classes, tutorials, external tutoring services and videos recordings offered to students. 
The response on level of engagement obtained in the survey was further applied to determine the interaction between the different student interventions. Students were incentivised to complete the survey by two gift vouchers offered for participation in the survey. The gift vouchers were awarded on a random selection basis by a person independent of the author of the study.

\section{Descriptive analysis and results of the multivariate regression}

The multivariate regression model was used to analyse the effect of the interaction of the various teaching interventions on student performance. Two self-developed constructs were developed, namely class attendance and alternatives to class attendance variables. These variables were constructed using the survey data obtained and by performing a reliability analysis using both cluster and factor analysis, in order to test for collinearity between variables. The results of the cluster and factor analysis indicated that traditional class attendance, beginners' class attendance, and tutorial class attendance variables were collinear, with a Cronbach's alpha of 0.686 , while beginners' videos, revision videos, and external tutoring services were collinear, with a Cronbach's alpha of 0.627. These results therefore support the creation of the two constructs, namely class attendance (consisting of the mean of traditional class attendance), beginners' class attendance, and tutorial class attendance variables; as well as the alternatives to class attendance variable (consisting of the mean of beginners' videos, revision videos, and external tutoring services). In addition to the two self-constructed variables, mentor sessions and WhatsApp participation were also included as variables of interest.

The variables of interest as collected by the survey, as well as final mark sheets, were identified and can be summarised as follows:

FM The final mark achieved by the student in the Financial Accounting 188 module in 2018, expressed on an ordinal scale of $0-100$, is the dependent variable.

The following were independent variables in the regression model:

A) The class attendance construct variable, which consisted of the following variables:

LA The percentage traditional class attendance in the Financial Accounting 188 module in 2018, expressed on an ordinal scale of $0-5$.

BA The percentage beginners' class attendance in the Financial Accounting 188 module in 2018, expressed on an ordinal scale of 0-5. 
TA The percentage tutorial class attendance in the Financial Accounting 188 module in 2018, expressed on an ordinal scale of $0-5$.

B) The alternatives to class attendance construct, which consisted of the following variables:

ET The percentage external tutoring attendance for the Financial Accounting 188 module in 2018, expressed on an ordinal scale of $0-5$.

BV The percentage beginners' videos watched in the Financial Accounting 188 module in 2018, expressed on an ordinal scale of $0-5$.

RV The percentage year-end revision videos watched in the Financial Accounting 188 module in 2018 , expressed on an ordinal scale of $0-5$.

C) Additional variables, which considered:

MA The percentage mentor session attendance in the Financial Accounting 188 module in 2018, expressed on an ordinal scale of $0-5$.

WP Participation in a Financial Accounting 188 WhatsApp group, expressed as Yes/No.

FT The first test mark was incorporated as a covariate indicator. The inclusion of the first assessment mark, measured on a scale of $0-100$, was included to reduce the scenario where students who were academically weaker in terms of performance by default attended more of the various methods above. The covariate thus allowed the model to determine whether the various methods above resulted in improved performance in the presence of an academic starting point.

\section{Grouping variables for regression results}

Based on an analysis of the characteristics of the population, it was noted that the sample could be divided into "prior exposure to financial accounting" and "no prior exposure to financial accounting" groups. The nature of the module, being an introduction to accounting, for which school-level accounting ${ }^{4}$ would have covered a large portion of the financial accounting modules syllabus, is a determining factor when considering the additional benefit certain interventions might have for the population. The "prior exposure to financial accounting" and "no prior exposure to financial accounting" classifications served as a grouping variable for further analysis. The multivariate regression model was therefore run throughout the study on three groups: firstly, the overall group of all respondents to the survey $(n=204)$; secondly, the two separate groups, namely the "prior exposure to financial accounting" group ( $\mathrm{n}=112)$; and 
thirdly, the "no prior exposure to financial accounting" group $(\mathrm{n}=92)$. This grouping is representative of the division between "prior exposure to financial accounting" and "no prior exposure to financial accounting" in the entire population.

\section{Perceptions of alternatives}

Finally, given the nature of external tutoring services - being externally managed and controlled with little input provided by the university - this study performed a further analysis on student perceptions of intervention alternatives to class attendance, which were obtained in order to further provide understanding as to student perceptions of certain alternatives available and to corroborate whether student perceptions were in line with the statistical findings on the contributions of these interventions to student performance.

\section{FINDINGS}

\section{Descriptive analysis}

The survey response data obtained regarding participation in the various teaching interventions employed, as well as the number of sessions provided for face-to-face contact sessions in the module, are displayed in Table 2.

Table 2: Student participation based on the number of students

\begin{tabular}{|l|c|c|c|c|c|c|}
\hline \multicolumn{1}{|c|}{$\mathbf{N}=\mathbf{2 1 0}$} & \multicolumn{6}{|c|}{ Number of students per participation level } \\
\hline \multicolumn{1}{|c|}{ Intervention } & None & $\mathbf{1 - 2 0 \%}$ & $\mathbf{2 0 - 4 0 \%}$ & $\mathbf{4 1 - 6 0 \%}$ & $\mathbf{6 1 - 8 0 \%}$ & $\mathbf{8 1 - 1 0 0 \%}$ \\
\hline $\begin{array}{l}\text { Traditional class } \\
\text { attendance }\end{array}$ & $0(0 \%)$ & $17(8 \%)$ & $16(8 \%)$ & $31(15 \%)$ & $36(17 \%)$ & $110(52 \%)$ \\
\hline $\begin{array}{l}\text { Beginners' class } \\
\text { attendance }\end{array}$ & $38(18 \%)$ & $70(33 \%)$ & $16(8 \%)$ & $32(15 \%)$ & $13(6 \%)$ & $41(20 \%)$ \\
\hline $\begin{array}{l}\text { Tutorial class } \\
\text { attendance }\end{array}$ & $18(9 \%)$ & $49(23 \%)$ & $24(11 \%)$ & $30(14 \%)$ & $31(15 \%)$ & $58(28 \%)$ \\
\hline $\begin{array}{l}\text { Beginners' video } \\
\text { watching }\end{array}$ & $41(20 \%)$ & $59(28 \%)$ & $26(12 \%)$ & $30(14 \%)$ & $17(8 \%)$ & $37(18 \%)$ \\
\hline $\begin{array}{l}\text { Revision video } \\
\text { watching }\end{array}$ & $21(10 \%)$ & $53(26 \%)$ & $26(12 \%)$ & $34(16 \%)$ & $26(12 \%)$ & $50(24 \%)$ \\
\hline $\begin{array}{l}\text { Mentor sessions, } \\
\text { WhatsApp group, } \\
\text { and external tutoring } \\
\text { participation }\end{array}$ & $\begin{array}{l}81 \%(\mathrm{n}=171) \text { of respondents indicated that they attended at least one mentor session } \\
\text { during the year, 32\% (n = 68) of respondents indicated that they participated in a } \\
\text { WhatsApp group for the module, and } 11 \% \text { ( } \mathrm{n}=23) \text { of respondents indicated that they } \\
\text { attended at least one external tutoring service session. }\end{array}$ \\
\hline
\end{tabular}

Valid responses were received from 204 students out of a potential population of 1247 students registered in 2018 for the Financial Accounting 188 module, representing 16 per cent of the population, which is deemed statistically representative of the student population.

Attendance, with the exception of traditional class attendance, for which the majority $(52 \%)$ of the respondents indicated that they attended more than 80 per cent of the classes, was 
distributed throughout the range. The variation in the distribution of responses suggests that students follow different approaches to the module based on their individual learning styles, and therefore various combinations of participation occur at various levels within the module.

Table 3 displays the descriptive characteristics of the survey respondents' final marks achieved, success in the module, gender, and home language.

Table 3: Descriptive analysis of the survey respondents' characteristics

\begin{tabular}{|c|c|c|c|c|}
\hline \multirow{2}{*}{ Descriptive data } & \multicolumn{4}{|c|}{ Final mark achieved } \\
\hline & Total & $0-49 \%$ & $50-74 \%$ & $75-100 \%$ \\
\hline Number of students per final mark range & 210 & 16 & 124 & 70 \\
\hline Percentage students in the range & $100 \%$ & $8 \%$ & $59 \%$ & $33 \%$ \\
\hline \multirow[t]{3}{*}{ Average grade in the range } & $64 \%$ & $29 \%$ & $59 \%$ & $82 \%$ \\
\hline & \multicolumn{4}{|c|}{ Student success } \\
\hline & Total & Fail & Pass & \\
\hline \multirow[t]{3}{*}{ Number of students passing/failing the module } & 210 & 16 & 194 & \\
\hline & \multicolumn{4}{|c|}{ Gender } \\
\hline & Total & Female & Male & \\
\hline \multirow[t]{3}{*}{ Gender of students } & 210 & 132 & 78 & \\
\hline & \multicolumn{4}{|c|}{ Home language } \\
\hline & Total & Afrikaans & English & Other \\
\hline Number of students per language group & 210 & 71 & 110 & 29 \\
\hline
\end{tabular}

\section{Statistical analysis}

\section{Results of the multivariate regression model}

In order to analyse the impact of the variables of interest on student performance, statistical analysis was performed using the students' participation responses and final marks achieved. This analysis was performed on the overall group of students, the group of students with prior exposure to financial accounting, and the group of students with no prior exposure to financial accounting.

\section{Overall combined group}

Table 4: Results for the overall combined group

\begin{tabular}{|l|c|c|c|}
\hline \multicolumn{1}{|c|}{$\mathbf{N = 2 0 4}$} & Coefficient & t-value & p-value \\
\hline Intercept & 37.597 & $\mathbf{5 . 8 7 9}$ & $\mathbf{0 . 0 0 0}$ \\
\hline Mentor sessions & 6.250 & 1.887 & 0.061 \\
\hline WhatsApp participation & 1.660 & 0.708 & 0.480 \\
\hline Class attendance construct & $\mathbf{2 . 1 0 2}$ & $\mathbf{2 . 0 8 0}$ & $\mathbf{0 . 0 3 9}$ \\
\hline Alternatives to class construct & -1.214 & -1.067 & 0.287 \\
\hline First test mark & $\mathbf{0 . 3 1 0}$ & $\mathbf{4 . 1 4 3}$ & $\mathbf{0 . 0 0 0}$ \\
\hline $\mathrm{R}=.369 ; \mathrm{R}^{2}=.136 ;$ Adjusted $\mathrm{R}^{2}=.114$ & & & \\
\hline
\end{tabular}


The results for the combined overall group, as displayed in Table 4, indicate that class attendance is statistically significant for student respondents with a $p$-value of $p<0.05$ on the regression test. A significant positive association ( $p$-value of 0.039 ) is reported between class attendance and students' final marks, which suggests that increased attendance of traditional classes, the beginners' classes, and tutorial classes have a significant positive impact (coefficient of 2.102) on students' final marks. This finding is consistent with prior literature that highlighted the importance of class attendance. Mentor session attendance $(p=0.061)$ and participation in a WhatsApp group $(p=0.480)$ were both found to have insignificant positive relationships, while the watching of videos (beginners and revision) and external tutor variables indicated an insignificant negative relationship. These findings suggest on an overall basis that the group of students benefited significantly from attending various classes compared to alternatives to class attendance such as mentor programmes, WhatsApp groups, watching videos, or attending external tutoring programmes.

\section{Students without prior exposure to financial accounting}

Table 5: Results for the students without prior exposure to financial accounting

\begin{tabular}{|l|c|c|c|}
\hline \multicolumn{1}{|c|}{$\mathbf{N = 9 2}$} & Coefficient & t-value & p-value \\
\hline Intercept & 27.537 & 3.074 & 0.003 \\
\hline Mentor sessions & 6.056 & 1.537 & 0.128 \\
\hline WhatsApp participation & 0.884 & 0.272 & 0.786 \\
\hline Class attendance construct & 4.384 & 2.956 & 0.004 \\
\hline Alternatives to class construct & 0.344 & 0.223 & 0.824 \\
\hline First test mark & $\mathbf{0 . 2 6 2}$ & $\mathbf{2 . 6 1 5}$ & $\mathbf{0 . 0 1 1}$ \\
\hline $\mathrm{R}=.472 ; \mathrm{R}^{2}=.222 ;$ Adjusted $\mathrm{R}^{2}=.177$ & & & \\
\hline
\end{tabular}

The results for the respondents who did not have prior exposure to accounting at school level, as displayed in Table 5, were consistent with the overall group. The significance of class attendance $(\mathrm{p}=0.004)$ for this group of students compared to the overall group is notable, which suggests that class attendance for this group is a crucial and significant factor for student success. The results of the "no prior exposure to financial accounting" group further support the overall finding that alternatives to class attendance do not compensate as an alternative delivery module for class attendance, where all alternative interventions, such as external tutoring, mentor programmes, and videos, indicate insignificant positive contributions to students' final marks. 
Students with prior exposure to financial accounting

Table 6: Results for the students with prior exposure to financial accounting

\begin{tabular}{|l|c|c|c|}
\hline \multicolumn{1}{|c|}{$\mathbf{N = 1 1 2}$} & Coefficient & t-value & p-value \\
\hline Intercept & 40.826 & 4.247 & $\mathbf{0 . 0 0 0}$ \\
\hline Mentor sessions & 5.934 & 0.999 & 0.320 \\
\hline WhatsApp participation & 2.218 & 0.648 & 0.518 \\
\hline Class attendance construct & 1.294 & 0.858 & 0.393 \\
\hline Alternatives to class construct & -1.321 & -0.692 & 0.491 \\
\hline First test mark & $\mathbf{0 . 3 1 0}$ & $\mathbf{2 . 6 6 6}$ & $\mathbf{0 . 0 0 9}$ \\
\hline $\mathrm{R}=.314 \mathrm{R}^{2}=.099$ Adjusted $\mathrm{R}^{2}=.056$ & & & \\
\hline
\end{tabular}

The results for the group that had prior exposure to the content of the module by completing accounting at a final school year/ Grade 12 level, as displayed in Table 6, suggested that no delivery model made a significant contribution to student success in terms of improved final marks as all variables reported insignificant relationships between the variables and the final marks. This finding of this study therefore presents an area for future research into further understanding which factors could significantly improve a student's final mark where a student had previously covered the majority of the contents of the module.

\section{Further analysis of the class attendance variable}

In order to further analyse the results of the class attendance construct variable, a best fit regression test was performed. The best fit regression test identified the two variables which provide the largest contribution to academic performance within the class attendance construct variable in the presence of the first test mark.

Table 7: Results of the best fit regression test

\begin{tabular}{|c|c|c|c|c|}
\hline \multicolumn{2}{|c|}{ Variables in order of significance } & Coefficient & t-value & p-value \\
\hline 1 & Tutorial attendance & 1.385 & 1.973 & 0.049 \\
\hline 2 & Beginner class attendance & 0.654 & 0.900 & 0.369 \\
\hline 3 & Traditional class attendance & \multicolumn{2}{|c|}{ Excluded from results } \\
\hline
\end{tabular}

The results of this best fit test, as displayed in Table 7, indicated that within the class attendance construct variable, tutorial attendance made the most significant positive contribution to the variable. This finding suggests that when analysed further, the nature of the class that a student attends has an influence on a student's success. This suggests that an increased level of attendance of tutorial classes provides a larger benefit to students in the presence of attending traditional classes and beginners' classes. This finding suggests that although students benefit 
from the traditional class environment, largely focused on covering theoretical aspects and showing students how to approach questions, students benefit from increased levels of having to solve problems on their own, with limited revision of theoretical concepts either obtained through prior knowledge or traditional class attendance, and having assistance available on demand. Tutorial classes also offer students an opportunity to immediately learn from mistakes by having their attempts marked and if these students have further questions on concepts or as to why they made mistakes, they receive immediate assistance. The acquisition of the theoretical component of the module can thus be achieved in various ways without a clear significant contributor to the students' learning.

\section{Further analysis of the alternatives to class attendance variable}

In order to further analyse the results of the alternatives to class construct variable, a best fit regression test was performed. The best fit regression test identified the two variables which provide the largest contribution to academic performance within the class attendance construct variable in the presence of the first test mark.

Table 8: Results of the best fit regression test

\begin{tabular}{|c|c|c|c|c|}
\hline \multicolumn{2}{|c|}{ Variables in order of significance } & Coefficient & t-value & p-value \\
\hline 1 & External tutoring & -2.481 & -1.769 & 0.078 \\
\hline 2 & Revision videos watched & 0.725 & 1.113 & 0.267 \\
\hline 3 & Beginners videos watched & \multicolumn{3}{|c|}{ Excluded from results } \\
\hline
\end{tabular}

The results of this best fit test, as displayed in Table 8, indicated that within the alternatives to class construct variable (which is a construct variable of video recordings, mentor (tutoring) sessions, and external tutoring) although found to make a statistically insignificant contribution to student performance, external tutor attendance was identified as the variable that approached the traditional threshold for statistical significance. This variable was significant at the 10 per cent level. It is important to note that this variable (external tutoring) had a negative coefficient. It could thus be deducted that external tutoring had a negative influence on student performance, albeit statically insignificant at the traditional 5 per cent level.

These findings further suggest that although providing videos of various classes aids students, watching a video does not necessarily compensate as an alternative to practising questions or attending classes. The knowledge transfer from watching a video to improved performance is thus not a significant factor to the average student's performance over an academic year.

The finding of external tutoring in the presence of class attendance not making a positive 
impact on student performance therefore creates an interesting area of research. It could be argued that students that perform poorer make increased use of external tutors. Reverse causality can therefore not be excluded, and as such these authors cannot conclude that external tutors cause students to perform poorer. Student perceptions of external tutoring were therefore obtained and analysed. These perceptions are discussed next in this study.

\section{Further analysis of external tutoring as an alternative to class attendance}

Due to the nature of external tutoring services being managed externally from the other possible interventions available, as well as the finding that increased levels of the use of the external tutoring services do not have a significant effect on students' academic performance in the presence of class attendance, data on students' perceptions of the external tutoring services available and used for the module were collected and analysed. The analysis of external tutoring services usage and student perceptions revealed that 90 per cent of the respondents indicated that they did not make use of external tutoring services, 4 per cent of the respondents indicated that they had attended one external tutoring session, and 6 per cent of the respondents indicated that they had attended an external tutoring session prior to an assessment, monthly or weekly. The next paragraph discusses the responses to various questions asked in the survey to understand student perceptions of certain interventions offered.

The students' perceptions of certain interventions acting as substitutes for other interventions indicated that the availability of videos, namely the beginners' videos and/or revision videos, resulted in using fewer external tutoring services for the module, where 83 per cent deemed the videos to act as a substitute for attending external tutoring services. Students further perceived external tutoring as a non-beneficial contributor to their academic performance, with 79 per cent of the respondents saying no, while 21 per cent of the respondents said yes when asked whether the respondent would recommend an external tutor to future students taking the module. As the external tutoring services are offered at a cost, the respondents were asked what they perceived to be a fair rate for external tutoring services. Of the respondents, 71 per cent indicated that they would be willing to pay R0 to R100 per session, 28 per cent indicated that they would be willing to pay between R101 and R200 per session, while only 1 per cent indicated that they were willing to pay more than R200 per session. This perception provides an interesting view that although a similar offering in the form of free mentoring sessions is offered, students are still willing to engage with external tutors at an additional cost to them, which suggests a perceived value attached to external tutoring services. It is further suggested that a possible reason for students engaging in paid tutoring services is that it provides them a basis for entitlement to make demands from a tutor which may not 
necessarily be achieved from the free mentoring sessions or a structured tutorial session.

Direct marketing (56\%) and word of mouth (24\%) appear to be the biggest factors that make students aware of external tutoring services. When asked to select reasons as to why a student would use external tutoring services, with the option of selecting as many options as applicable, preparation prior to an assessment in the form of a crash course was the leading reason students perceived external tutoring to be relevant, followed by revision of prior test/examination papers. Revision of theory, help with completing electronic assessments, and help with questions specifically prepared by external tutors were perceived to have the least relevance as to why students would make use of external tutoring services.

\section{Robustness test}

In order to test the results of the regression model for robustness, a best predictors analysis was performed, where the best predictors of student success were identified, namely tutorial attendance and external tutor attendance, including the covariate variable, namely FT mark, which analysed the impact of these three variables on student performance in terms of a final mark. The results for the entire group of students, as well as the "no prior exposure to accounting group", indicated significant positive relationships between student performance and tutorial attendance $(p=0.039$ and $p=0.004$ respectively). These findings are consistent with the findings above that increased levels attending classes, specifically tutorial classes, made a significantly positive contribution to student performance. It is further noteworthy, although insignificant, that for both groups increased levels of external tutoring services had a negative impact on student performance.

\section{CONCLUSION}

In understanding the effect of various teaching interventions on students' academic success, this study followed the approach of analysing the effect of various teaching interventions in an environment where multiple interventions are offered. The multiple-intervention environment creates a setting where students can elect to make use of interventions, often based on their perceptions of what effect the interventions will have on their academic performance. The study utilised self-developed constructs, namely class attendance and an alternatives to class attendance construct. The study found that, consistent with prior literature, increased levels of student attendance of various classes, as captured by the class attendance construct, have a significant positive relationship with student performance, as well as that the nature and format of the class could be a driver for student success.

Examining the nature of classes presented within the class attendance construct identified 
various teaching styles, varying from traditional classes being both theory and practice based in terms of providing guidance in completing questions, with a minimal component of individual or group work. Beginners' classes are purely practical classes with limited revision of theory with limited individual or group work. On the other hand, tutorial classes are purely practical exercises, where assignments are completed individually or in groups, with lecturer and peer assistance to explain theoretical concepts and provide guidance on completing questions only when needed.

The findings of this study suggest that class attendance, which has previously been identified as the most significant contributor to student success in terms of academic performance, should be redefined. While attendance was key to identify the main driver of success, the level of participation in these classes would be the true driving force in the development of academic interventions. In a multiple-intervention environment, it is noted that students benefit most significantly from classes where they could follow a hands-on approach, applying their own approach to applying and understanding theoretical knowledge, and receiving assistance and guidance on demand. This suggests that increased levels of tutorialstyle classes provide the most beneficial use of a student's time.

The findings further suggest that all interventions are not equal contributors to student success, noting that many interventions that are perceived to make positive impacts on student success are not necessarily suitable interventions that can be used to significantly increase student performance. It is however noted as a limitation of this study that the interaction of various interventions has been measured in a combined view with other variables influencing the ideal suggested interaction, when analysed in isolation the interaction of the variables may have a potentially different impact on student performance, conditions for an ideal interaction presents an area for future research. The implications of these findings therefore provide a clearer direction that could be explored in the future and integrated into the educational policymaking process and strategic planning to address the failure rates at South African universities.

\section{NOTES}

1. Attendance is compulsory for students who did not have accounting at a Grade 12 school level. All students are, however, strongly encouraged to attend.

2. Classes, tutorials, and the mentoring programme are part of the students' course module fees and presented at no separate additional cost to the course fee.

3. Students attend one session out of four available time slots of one hour each.

4. "Prior exposure to financial accounting" is defined as having accounting as a subject at Grade 12 / final school year level. 


\section{REFERENCES}

Bignoux, S. and K. J. Sund. 2018. Tutoring executives online: What drives perceived quality? Behaviour and Information Technology 37(7): 703-713.

Bokana, K. G. and D. D. Tewari. 2014. Determinants of student success at a South African university: An econometric analysis. Anthropologist 17(1): 259-277.

Colver, M. and T. Fry. 2016. Evidence to support peer tutoring programs at the undergraduate level. Journal of College Reading and Learning 46(1): 16-41.

Cooke, T. E. and R. S. O. Wallace. 1990. Financial disclosure regulation and its environment: A review and further analysis. Journal of Accounting and Public Policy 9(2): 79-110.

CHE see Council on Higher Education.

Council on Higher Education. 2013. A proposal for undergraduate curriculum reform in South Africa: The case for a flexible curriculum structure report of the task team on undergraduate curriculum structure. Pretoria: CHE.

De Jager, E. and E. Blitzer. 2013. First-year students' participation. International Business \& Economics Research Journal 12(4): 399-414.

Devadoss, S. and J. Foltz. 2006. Evaluation of factors influencing student class attendance and performance. American Journal of Agricultural Economics 78(3): 499-507.

Horn, P. and A. Jansen. 2009. Tutorial classes - why bother? An investigation into the impact of tutorials. South African Journal of Economics 77: 179-189.

Mahlangu, T. P. and W. J. F. Fraser. 2017. The academic experiences of grade 12 top achievers in maintaining excellence in first-year university programmes. South African Journal of Higher Education 31(1): 104-118.

Papageorgiou, E. 2019. Lecture attendance versus academic performance and prior knowledge of accounting students: An exploratory study at a South African university. South African Journal of Higher Education 33(1): 262-282.

Romer, D. 1993. Do students go to class? Journal of Economic Perspective 7(3): 167-174.

Schmulian, A. and S. Coetzee. 2011. Class absenteeism: Reasons for non-attendance and the effect on academic performance. Accounting Research Journal 24(2): 178-194.

Sriprakash, A., H. Proctor and B. Hu. 2016. Visible pedagogic work: Parenting, private tutoring and educational advantage in Australia. Discourse 37(3): 426-441.

Steenkamp, L. P., R. S. Baard and B. L. Frick. 2015. Factors influencing success in first-year accounting at a South African university: A comparison between lecturers' assumptions and students' perceptions. South African Journal of Accounting Research 23(1): 113-140.

Steenkamp, L. P. and P. L. Wessels. 2009. An investigation into students' perceptions of accountants. Meditari Accountancy Research 17(1): 117-132.

Van Walbeek, C. 2004. Does lecture attendance matter? Some observations from a first-year economics course at the University of Cape Town. South African Journal of Economics 72(4): 861-883. 